International Journal of Biology, Pharmacy and Allied Seiences (IJBPAS)

'A Bridge Betueen Caboratory and QRando'

WwW.ibpas.com

\title{
DOES PERCEIVED ORGANISATIONAL SUPPORT DRIVE HEALTHCARE PROFESSIONALS' INVOLVEMENT IN MATERNAL AND CHILD HEALTH POLICY?
}

\section{DR. IMMANUEL AZAAD MOONESAR R.D.}

President, Academy of International Business - MENA Chapter, Assistant Professor- Health Policy, Mohammed Bin Rashid School of Government (formerly Dubai School of Government), Level 7, Convention Tower, P.O. Box 72229, Dubai, UAE *Corresponding Author: E Mail: Immanuel.moonesar@mbrsg.ac.ae; Phone: +97143175533; Fax: +9714-3293291

Received 19 ${ }^{\text {th }}$ Jan. 2019; Revised $10^{\text {th }}$ Feb. 2019; Accepted $19^{\text {th }}$ March 2019; Available online $1^{\text {st }}$ Sept. 2019 https://doi.org/10.31032/IJBPAS/2019/8.9.4784

\section{ABSTRACT}

Introduction: Research in the field of Maternal and Child Health (MCH) has grown over the past decade and has become a global topic of interest and debate for health professionals, policy-makers, government entities, and academics.

Objectives: The aim of the study was to identify levels of influence United Arab Emirates healthcare professionals and practitioners have on policy influence on involvement for improving and lowering $\mathrm{MCH}$ mortality rates.

Methods: The theoretical framework focused on how to utilize the Andersen model in exploring the factors associated with $\mathrm{MCH}$ care professionals and practitioners who are involved in policy-making and development. A correlational research design was used to determine whether healthcare employees and practitioners exert influence in the policymaking and adoption process for the improvement of $\mathrm{MCH}$.

Results: The enabling factors such as the level of perceived organizational support and, the 5 phases of policy-making process helped to determine whether or not there was a relationship/ association existing. 
Conclusion: Organizational support was statistically significant with each of the policymaking stages and may be considered in the future of responding to the United Nations Sustainable Development Goals 2030.

\section{Keywords: Health Policy, Maternal and Child Health, United Arab Emirates, Andersen}

\section{Model, Perceived Organisational Support}

\section{INTRODUCTION}

In recent years, improving maternal and child health $(\mathrm{MCH})$ has increasingly become a global mandate with increased emphasis being placed on research related to interventions for reducing the mortality rates of mothers and children. ${ }^{1}$ Annually, over 3 million babies die worldwide, primarily due to complications during birth, prematurity, and preventable or treatable diseases, including infections. ${ }^{1,2}$ Within developing countries, over 40 million women give birth in the premises of their home without any assistance from health professionals and practitioners. ${ }^{1,2,3}$ Daily, over 800 women die during pregnancy or delivery, and there are 8,000 deaths of newborn babies. ${ }^{3}$ The aim of the study was to identify levels of influence United Arab Emirates healthcare professionals and practitioners have on policy influence on involvement for improving and lowering $\mathrm{MCH}$ mortality rates.

\section{History of Maternal and Child Health}

In the 19th century, the Eastern Mediterranean Region (EMR) countries such as Bahrain, Kingdom of Saudi Arabia and Oman and also cities such as Cairo, Istanbul, and Levant, which all embraced the concept of public health to improve the health status of the citizens. However, research studies ${ }^{1,2,3}$ have shown improving public health policy and practices were successful as the movement towards the adoption of international measures occurred during the 20th century.

In the first half of the 20th century, there was a growth of healthcare establishments across the EMR. By 1948, a main priority of the World Health Organisation (WHO) focused on the $\mathrm{MCH}$ policies and still remains as such. In the mid-1980s, a series of critical MCH issues were highlighted, including haemorrhage, abortion, infection, eclampsia, obstructed labour, pneumonia, prematurity, birth asphyxia, and diarrhea ${ }^{4}$ Several international conferences such as the 1985 World Conference to Review and Appraise the Achievements of the United Nations Decade for Women and forums such as 2013 Saving Mothers and Children created an initial awareness of the challenges. This raising of awareness resulted in the launch in 2000 of Millennium Development Goals (MDGs) 4 and 5 to improve $\mathrm{MCH}$ and then later in the 
United Nations $2030 \quad$ Sustainable

Development Goal number 3.

\section{Maternal and Child Health Research}

In the last twenty years, research in the field of $\mathrm{MCH}$ has grown over the past few decades. ${ }^{5}$ According to the Eastern Mediterranean Health Journal editors, within the EMR, MCH has become a topic of debate among governments, policymakers and academics 5,6,7. $\mathrm{MCH}$ researchers have primarily focused on health services and care ${ }^{5}$. There has been limited research on the role of health professionals in the $\mathrm{MCH}$ policy-making and development process ${ }^{3,5,8,9}$.

Consequently, there is a gap in understanding the role and importance of $\mathrm{MCH}$ professionals in policy development and implementation, in addition to the lack of research on the subject. ${ }^{5}$ Results from this study help to bridge the gap between health practitioners and applied research in understanding whether and how health professionals play a role in the $\mathrm{MCH}$ policy-making process. Across EMR countries, statistics show that over 39,000 women die because of pregnancy-related complications, while approximately 923,000 children under the age of 5 die every year ${ }^{4,10}$. Addressing this problem was critical within the EMR in addressing the underlying problem of elevating maternal and child mortality rates.

\section{Current Trends and Debates}

Ten MDG 4 and MDG 5 priority countries within the EMR are struggling with adoption of the policies and strategies towards improving $\mathrm{MCH}$. These include Afghanistan, Djibouti, Egypt, Iraq, Morocco, Pakistan, Somalia, South Sudan, Sudan, and Yemen. ${ }^{4}$ These countries have over $90 \%$ of maternal deaths in the region. ${ }^{4}$ From these maternal deaths, $70 \%$ are caused by pregnancy-related complications, such as haemorrhage, abortion, infection, eclampsia, and obstructed labor. ${ }^{4,11} 60 \%$ of the child mortality rates are due to preventable causes within the EMR, such as pneumonia, prematurity, birth asphyxia, and diarrhoea. ${ }^{4,11}$ The countries of the EMR have adopted a number of strategies for improving $\mathrm{MCH}$ as reported in conjunction with the MDG 4 and MDG 5 Countdown Initiatives $^{4,12}$.

Governments across the EMR were encouraged to implement health systems, policies, and mandates to promote better maternal and childcare. At the recent 2013 Saving Mothers and Children conference held in Dubai, UAE, many of the ministers of public health within the EMR expressed their commitment and dedication towards improving $\mathrm{MCH}$ care in relation to health system performance, policies, and strategies, trends of health status, disease surveillance, and routine reporting ${ }^{13}$. At 
the recent 2013 Saving Mothers and Children conference held in Dubai, UAE, many of the priority countries within the EMR are experiencing a shortage of health professionals and practitioners such as doctors, midwives, and nurses, in addition to an unequal distribution of financial investments for training and development in policy-making ${ }^{5,7,10}$. The Countdown Initiatives ${ }^{7}$ were developed almost a decade ago, with the purpose of supporting, driving, and monitoring the implementation of the MDGs with a particular focus on improving the $\mathrm{MCH}$. The first Countdown Conference launched its initiatives in London, England in 2005. Implementation of these Countdown Initiatives occurred across the EMR through policies and strategies in favour of improving the MCH. ${ }^{14}$

\section{Research Inquiry}

The aim of this study was to identify levels of influence health professionals and practitioners have on policy involvement ${ }^{10}$, ${ }^{12}$ for improving and lowering $\mathrm{MCH}$ mortality rates. Therefore, the research question was: "To what extent, if any, does the level of support from the institution of employment of the $\mathrm{MCH}$ professional relate to the level of influence in policymaking?"

$H_{o}$ : There is no relationship between the level of support from the institution of employment of the
$\mathrm{MCH}$ professional and the level of influence in policy-making.

$H_{a}$ : There is a positive relationship between the level of support from the institution of employment of the $\mathrm{MCH}$ professional and the level of influence in policy-making.

The level of support from the institution of employment was another IV and was measured as a categorical variable adapted from the perceived organizational support model established by Eisenberger et al. (1986). Four items were selected from the Survey for Perceived Organizational Support (POS) ${ }^{15}$ where prior studies have provided evidence of reliability and validity of this instrument ${ }^{16}$. In a recent study, the level of organizational support, an IV, was found to have a relationship with the policy-making process. ${ }^{17}$ Four items of the POS survey questions for the study were included as follows:

1. The organization takes pride in my accomplishments.

2. The organization really cares about my well-being.

3. The organization values my contributions to its well-being.

4. The organization strongly considers my goals and values.

Each of the four items had scale anchors from 1 (strongly disagree) to 5 (strongly agree ${ }^{18}$. This variable was associated with the enabling factors phase of the Andersen 
model 19, 20, 21 . The Andersen model of healthcare services utilization was developed by Andersen (1968) to examine healthcare settings and processes 19,20,21. There are limited research on the study topic of policy-making and development and its' influence on reducing mortality rates in relation to the use of the Andersen model. This theoretical framework focused on how to utilize the Andersen model in exploring the factors associated with $\mathrm{MCH}$ care professionals and practitioners involved in policy-making and development. There were four phases involved in the making of the Andersen Model. Therefore, for the above research question and hypotheses, the dependent variable (DV) was the same, where the level of policy-making influence was on the range of the scale of 1 to 5 . This DV was a discrete variable where the respondents entered only values of $1,2,3,4$, and 5 . The research question and hypotheses were used to determine whether a relationship/association existed between the IV and DV sets.

\section{MATERIALS \& METHODS}

The IVs within the study included the perceived organizational support of the health professionals and practitioners within UAE. The DVs included the five phases of the policy-making process and development, that is, policy preparation, policy formation, policy adoption and legitimization, policy implementation, and policy assessment and evaluation.

\section{Study population}

The quantitative methodology included the data collection of a sample of the population of health professionals and practitioners involved in the $\mathrm{MCH}$ care and management across the UAE. According to reports from the UAE National Bureau of Statistics data for 2011, the total population of the UAE health professionals and practitioners was $34,603 .^{22}$ The population in 2011 was comprised of 2,796 health professionals and practitioners working at health centers affiliated with the UAE Ministry of Health, 5,624 working at hospitals affiliated with the UAE Ministry of Health, 5,580 working at government health establishments, and 20,603 working at private health centers and hospitals. From these 34,603 healthcare professionals and practitioners, there were 7,850 working within the field of $\mathrm{MCH}$ and, therefore, this was the study population. Based on the statistical sample size table ${ }^{21,22}$ and reference to a sample size calculator (with a $5 \%$ margin of error), ${ }^{23,24}$ confidence level as $95 \%$ and study population size as 7,850 and the response distribution as $50 \%$, the minimum sample size for the study was 366 health professionals and practitioners involved in the $\mathrm{MCH}$ care across the UAE.

\section{Database}


A database was developed identifying $\mathrm{MCH}$ professionals and practitioners in the UAE. The database development complied with similar steps as exhibited by Chan et al. $(2011)^{25}$ included establishing a set of standardized data set elements. The $\mathrm{MCH}$ professionals' information was gathered into one repository. This database was not made public to anyone except me. A survey instrument was designed along the constructs of allowing many of the participants to provide answers to the questions with a result of producing a large number of variables. The participants were surveyed voluntarily. The data information collected from the surveys in the form of the IV and DV sets were then analysed using statistical approaches of correlations such as multivariate analysis and multiple regressions from the SPSS program.

\section{Instrumentation}

The instrument survey questionnaires were developed in English language only and disseminated via online mechanisms for the correlational research study. Initially, pilot testing of the survey instrument included information about the informed consent form, the survey's objectives, benefits and any potential risks. The Cronbach's Alpha was conducted using SPSS to determine the reliability of the survey instrument. The reliability coefficient of all the items was higher than 0.80 which is considered as "acceptable" in most social science research situations.

\section{Statistical Analyses}

Qualtrics software was used for collecting the data of the survey. Qualtrics software provided the flexibility to design the survey. The data collected was exported in file formats such as SPSS, Microsoft Word, and Microsoft Excel and were exported in both forms as coded values or coded text. Within the Qualtrics survey system, the data were exported in a format as the Statistical Package for the Social Sciences (SPSS). Data cleaning and screening procedures were applied to the exported SPSS survey data. One way that the data were cleaned was through the scanning of data for errors or unexpected characters through the checking of the 'frequencies' for each variable. ${ }^{26}$

The frequency was found using the SPSS program and proceeding to Analyze $\rightarrow$ Descriptive Statistics $\rightarrow$ Frequencies. The variables of the survey were to be checked in terms of frequencies. One way for screening the data was through the 'Crosstabs' function within the SPSS program and proceeding to Analyze $\rightarrow$ Descriptive

Statistics $\rightarrow$ Crosstabs. This function displayed a matrix of the frequency of two variables. These descriptive statistics frequency tables were used to illustrate the 
quantitative descriptions into manageable forms.

A correlational research design was used to determine whether health professionals and practitioners exert influence in the policymaking and adoption process for the improvement of $\mathrm{MCH}$. The enabling factors (IV) such as level of perceived organizational support and, the 5 phases of policy-making process (DVs) helped to determine whether there was a relationship/association existing or not, between IV \& DV sets. The sample size of the study was $380 \mathrm{MCH}$ practitioners and professionals of the UAE. A survey instrument was developed and pilot testing was conducted. The final survey was approved; this was then disseminated to the participants for their responses. The data were collected via online survey system, Qualtrics. Ethical procedures followed and adhered to the IRB guidelines and the IRB application was submitted.

\section{Ethics Approvals}

The survey instrument included an application for ethics adherence, and clearance and approval of the Institutional Review Board (IRB) in the United States of America.

\section{RESULTS}

The organizational support was valued as 1 = strongly disagree, 2 = disagree, $3=$ neutral, $4=$ agree, and $5=$ strongly agree.With reference with Table 1, the average total mean for the perceived organizational support level was $M=3.87$, thus indicating at least $77.4 \%$ of respondents agreed that their respective place of employment provided some level of organizational support.

A Spearman correlation was used to determine the relationship between perceived organizational support (POS) and policy preparation (phase 1). For the policy preparation (phase 1), Table 2 shows that the significant Spearman correlation coefficient value of 0.507 was a moderate positive monotonic correlation between the policy preparation (phase 1) and POS, $\mathrm{r}_{\mathrm{s}}=0.507, \mathrm{n}=378, \mathrm{p}<0.01$ According to SPSS, the $p$-value for this test as being $p<$ .001 in Table 2 , there is moderate evidence to reject the null hypothesis $\left(\mathrm{H}_{0}\right)$, that is, there is some evidence to suggest that POS and the policy preparation (phase 1) are positive monotonically correlated in the population.

A Spearman correlation was used to determine the relationship between POS and policy formation (phase 2). For the policy formation (phase 2), Table 2 shows that the significant Spearman correlation coefficient value of 0.517 was a moderate positive monotonic correlation between the policy formation (phase 2) and POS, $\mathrm{r}_{\mathrm{s}}=0.517, \mathrm{n}=378, \mathrm{p}<0.01$. According to SPSS, the $\mathrm{p}$-value for this test as being $\mathrm{p}<$ .001 in Table 2, there is moderate 
evidence to reject the null hypothesis $\left(\mathrm{H}_{0}\right)$, that is, there is some evidence to suggest that POS and the policy formation (phase 2) are positive monotonically correlated in the population.

A Spearman correlation was used to determine the relationship between POS and policy adoption and legitimization (phase 3). For the policy adoption and legitimization (phase 3), Table 2 shows that the significant Spearman correlation coefficient value of 0.478 was a moderate positive monotonic correlation between the policy adoption and legitimization (phase 3) and POS, $r_{s}=0.478, n=378, p<$ 0.01. According to SPSS, the p-value for this test as being $\mathrm{p}<.001$ in Table 2 , there is moderate evidence to reject the null hypothesis $\left(\mathrm{H}_{0}\right)$, that is, there is some evidence to suggest that POS and the policy adoption and legitimization (phase 3 ) are positive monotonically correlated in the population.

A Spearman correlation was used to determine the relationship between POS and policy implementation (phase 4). For the policy implementation (phase 4), Table 2 shows that the significant Spearman correlation coefficient value of 0.417 was a moderate positive monotonic correlation between the policy implementation (phase 4) and POS, $\mathrm{r}_{\mathrm{s}}=0.417, \mathrm{n}=378, \mathrm{p}<0.01$. According to SPSS, the $\mathrm{p}$-value for this test as being $\mathrm{p}<$
.001 in Table 2, there is moderate evidence to reject the null hypothesis $\left(\mathrm{H}_{0}\right)$, that is, there is some evidence to suggest that POS and the policy implementation (phase 4) are positive monotonically correlated in the population.

A Spearman correlation was used to determine the relationship between POS and policy assessment and evaluation (phase 5). For the policy assessment and evaluation (phase 5), Table 2 shows that the significant Spearman correlation coefficient value of 0.436 was a moderate positive monotonic correlation between the policy assessment and evaluation (phase 5) and POS, $r_{s}=0.436, n=378, p<$ 0.01. According to SPSS, the p-value for this test as being $\mathrm{p}<.001$ in Table 2 , there is moderate evidence to reject the null hypothesis $\left(\mathrm{H}_{0}\right)$, that is, there is some evidence to suggest that POS and the policy assessment and evaluation (phase $5)$ are positive monotonically correlated in the population.

A Spearman correlation was used to determine the relationship between POS and the combined policy-making phases. For the combined policy-making phases, Table 2 shows that the significant Spearman correlation coefficient value of 0.529 was a moderate positive monotonic correlation between the combined policymaking phases and POS, $\mathrm{r}_{\mathrm{s}}=0.529, \mathrm{n}=378$, $p<0.01$. According to SPSS, the $p$-value 
for this test as being $\mathrm{p}<.001$ in Table 2 , there is moderate evidence to reject the null hypothesis $\left(\mathrm{H}_{0}\right)$, that is, there is some evidence to suggest that POS and the policy-making phases are positive monotonically correlated in the population.

Overall, the results for RQ indicate that POS moderately related to the policy- making phases. There was a statistical relationship between POS and each of the policy-making phases according to Table 3. There is moderate evidence to reject the null hypothesis $\left(\mathrm{H}_{0}\right)$, that is, there is some evidence to suggest that POS and each of the policy-making phases and combined are positive monotonically correlated in the population.

Table 1: Organizational Support Level Results of the Study Sample

\begin{tabular}{|c|c|c|c|c|c|c|c|c|}
\hline$\#$ & Statement & $\begin{array}{c}\text { Strongly } \\
\text { agree }\end{array}$ & Agree & Neutral & Disagree & $\begin{array}{l}\text { Strongly } \\
\text { disagree }\end{array}$ & $\begin{array}{c}\text { Total } \\
\text { responses }\end{array}$ & Mean \\
\hline 1 & $\begin{array}{c}\text { My place of work/ } \\
\text { organization takes pride in } \\
\text { my accomplishments }\end{array}$ & $14.3 \%$ & $66.6 \%$ & $13.2 \%$ & $4.2 \%$ & $1.6 \%$ & 378 & 3.88 \\
\hline 2 & $\begin{array}{l}\text { My place of work/ } \\
\text { organization really cares } \\
\text { about my well-being }\end{array}$ & $23.8 \%$ & $50.0 \%$ & $19.5 \%$ & $5.0 \%$ & $1.6 \%$ & 378 & 3.89 \\
\hline 3 & $\begin{array}{c}\text { My place of work/ } \\
\text { organization values my } \\
\text { contributions to its well- } \\
\text { being }\end{array}$ & $21.7 \%$ & $50.5 \%$ & $21.7 \%$ & $4.2 \%$ & $1.8 \%$ & 378 & 3.86 \\
\hline 4 & $\begin{array}{c}\text { My place of work/ } \\
\text { organization strongly } \\
\text { considers my goals and } \\
\text { values. } \\
\text { Overall Organizational }\end{array}$ & $18.2 \%$ & $57.9 \%$ & $17.4 \%$ & $4.2 \%$ & $2.1 \%$ & 378 & 3.86 \\
\hline & Support Means & $19.5 \%$ & $56.3 \%$ & $18.0 \%$ & $4.4 \%$ & $1.8 \%$ & 378 & 3.87 \\
\hline
\end{tabular}

Table 2: Relationship Between Organizational Support And Policy-Making Phases

\begin{tabular}{|c|c|c|}
\hline \multicolumn{2}{|c|}{ Spearman's rho $\left(r_{s}\right)$ Correlations } & \multirow{3}{*}{$\begin{array}{c}\text { Perceived Organizational } \\
\text { Support (POS) } \\
.507^{* *} \\
.000\end{array}$} \\
\hline Policy preparation & Correlation Coefficient & \\
\hline (phase 1) & Sig. (2-tailed) & \\
\hline & $\mathbf{N}$ & 378 \\
\hline Policy formation & Correlation Coefficient & $.517^{* * *}$ \\
\hline (phase 2) & Sig. (2-tailed) & .000 \\
\hline \multirow{4}{*}{ Policy adoption and legitimization (phase 3) } & $\mathbf{N}$ & 378 \\
\hline & Correlation Coefficient & $.478^{* *}$ \\
\hline & Sig. (2-tailed) & .000 \\
\hline & $\mathbf{N}$ & 378 \\
\hline \multirow{3}{*}{$\begin{array}{l}\text { Policy implementation } \\
\text { (phase 4) }\end{array}$} & Correlation Coefficient & $.417^{* *}$ \\
\hline & Sig. (2-tailed) & .000 \\
\hline & $\mathbf{N}$ & 378 \\
\hline \multirow{3}{*}{ Policy assessment and evaluation (phase 5) } & Correlation Coefficient & $.4366^{* *}$ \\
\hline & Sig. (2-tailed) & .000 \\
\hline & $\mathbf{N}$ & 378 \\
\hline \multirow[t]{3}{*}{ Combined Policy-making Phases } & Correlation Coefficient & $.529^{* *}$ \\
\hline & Sig. (2-tailed) & .000 \\
\hline & $\mathbf{N}$ & 378 \\
\hline
\end{tabular}

Note. **. Correlation is significant at the 0.01 level (2-tailed). 
Table 3: Summary Of Relationship And Predictors Between Variables And Policy-Making Phase

\begin{tabular}{|c|c|c|c|c|}
\hline \multicolumn{2}{|c|}{ Spearman's rho $\left(r_{\mathrm{s}}\right)$ Correlations } & Policy-making & Decision & Regression Model \\
\hline \multirow{2}{*}{$\begin{array}{c}\text { Perceived } \\
\text { Organizational Support } \\
\text { (POS) }\end{array}$} & Correlation Coefficient & $.529^{* *}$ & RQ: Reject the $\mathrm{H}_{0}$ & An Important Predictor \\
\hline & Sig. (2-tailed) & & & $(42 \%)$ \\
\hline & **. Correlation & $\begin{array}{l}\text { nificant at the } 0 \\
N=380 \\
\text { justed } R^{2}=0.41\end{array}$ & & \\
\hline
\end{tabular}

\section{DISCUSSION}

The level of support from the institution of employment was another independent variable and measured as a categorical variable adapted from the perceived organizational support model established by Eisenberger et al., 1986 as mentioned earlier. The level of organizational support, an independent variable, found to have a relationship with the policy-making process in a recent study with the findings of a relationship. ${ }^{17}$ This variable associated with the enabling factors phase of the Andersen Model. ${ }^{19,20,21}$ Researchers have found that policy involvement may have very close meaning to the concept of influence on policy. ${ }^{27}$ The research studies were limited mainly to health professionals and practitioners' involvement and influence in health policy-making processes. In a recent study of Saudi Arabian physicians, 93\% lacked research training which was perceived as a lack of organizational support. ${ }^{17}$

Overall, the results for RQ indicate that POS moderately related to the policymaking phases. POS and each of the policy-making phases were related. A recent study by Weber et al., (2011) shows that the introduction of a new breastfeeding policy is significant to enabling factors such as organizational support for the employees. ${ }^{28}$ The study also highlighted that having a positive attitude towards breastfeeding in the workplace is significantly improved by the likelihood of policy success. ${ }^{29,30}$

The findings are consistent with prior assessments of perceived organizational support which influenced the advancement of evidence-based decisionmaking in the field of $\mathrm{MCH} \cdot{ }^{31}$ Klerman et al., (2007) found that availability of family planning facilities varied in structure and organization which impacted on policy reform across federal and state levels. $^{32}$ Effective $\mathrm{MCH}$ policy and practice were found to have some significance on more scientific and organizational support to address the MCH needs effectively. ${ }^{33}$

Therefore, this argument provides motive to consider that the perceived organizational support of health professionals and practitioners do not differ much at the various phases of the policymaking process. In order for professionals to have a positive impact on the 
development of policies it may be critical to understand and implement enabling factors such as organizational support, employing highly-skilled and competent healthcare professionals, and ensuring that professionals come from a variety of countries.

The $\mathrm{MCH}$ leadership may transfer this knowledge across those priority countries within the EMR as best practice. It may critical to understand why practitioners' involvement in the policy making process is important. Having the enabling factors embedded in organizational policy such as increasing organizational support, and employing highly-skilled and competent individuals from a variety of countries, practitioners may be more suited and ready to be involved in the policy-making process. Furthermore, the $\mathrm{MCH}$ leadership may review the current health policy systems in the UAE to include enabling factors for increased involvement and influence.

Findings from the study clarified that nationality, education, and organizational support are contributing factors to the policy-making influence. The question for EMR government leaders and decisionmakers was to understand why the UAE is successful in lowering mortality rates and how can they learn from the UAE. Therefore, the knowledge gained, provides for policies and organizational awareness for healthcare professionals and decisionmakers to create an environment that encourages policy-making involvement via organizational support activities.

\section{Study Limitations}

One of the limitations was that the health professionals and practitioners had perceptions that their current leadership skills and competencies were being assessed and evaluated; therefore, they may have expressed more textbook theories than the actual reality of the policy-making process. Efforts were made to acquire participants' involvement via online surveys, taking into account the ethical implications of the online survey research methodology. The advantages of the survey method as the measurement instrument were used for validity and reliability. This includes being inexpensive; valid for wellconstructed and substantiated surveys; superior to measuring attitudes and obtaining insights; and useful for exploration in addition to hypothesis testing research. ${ }^{34}$ Additional limitations resulted from the research techniques employed since correlational research did not indicate causation. The correlational method only uncovered relationships between the IV and DV and, therefore, did not determine a conclusive reasoning as to why the relationship existed. From the data, some of the IVs such as nationality and organizational support had a positive effect 
on the policy-making process. As a result, the data was unable to conclude which variables caused the other. Three ways in which the IV and DV may causally relate are through a particular IV causing DV (either directly or indirectly); DV causes a particular IV (either directly or indirectly); or a third variable causes both IV and DV. The focus of study was determining whether or not the IVs had influence on the policy-making process, rather than revealing which variables influence each other. Therefore, reasons for the relationships cannot be determined until further research is done.

\section{CONCLUSIONS AND PERSPECTIVES}

The research findings suggested that enabling factors such as the perceived organizational support had some level of influence in the policy-making process to inform policy and program efforts from the improvement of $\mathrm{MCH}$. However, more research is needed to determine the additional factors to influence policymaking. The researchers acknowledged the need for 'future unpacking' of the healthcare systems ${ }^{5}$ and processes to allow for a deeper understanding and the challenges use the Andersen Model ${ }^{14}$. The findings of the study were successful in confirming the future need for a deeper understanding of the healthcare systems and processes particularly, policy-making.
The research agenda was addressed from the results of this study which revealed that there were statistical correlations and that the significant predictor of policy-making was organizational support that uniquely explained the $42 \%$ of the variation in policy-making. The research adds value to decision-makers in considering the extent of maternal and child health policy, laws, and regulations that could assist in evaluating the success in realizing current challenges and strategies of health policies and legislation. The research findings could positively influence decision makers' action plans in formulating new guidelines, and public policies and strategies for the development of maternal and child health across the UAE and its regions in light of responding to the Global Goals of the SDGs. Future research should nevertheless aim to include other factors such as gender, performance appraisals, training, knowledge and innovation, legal frameworks and institutional structures that may have an influence on the policymaking process as a whole, or at each of the phases of the policy-making process.

\section{Conflicts of interest:}

The authors declare that there are no conflicts of interest.

\section{Funding for this study}

No outside funding was received to conduct this study. This study was self-supported. 


\section{ACKNOWLEDGEMENTS}

I would like to thank Dr Jim Goes, Walden University for the direction and guidance in pursuing this study and the Mohammed Bin Rashid School of Government for helping in using the survey software for the data collection.

\section{Supplementary Materials:}

Readers may contact the main author for supplementary materials on immanuel.moonesar@mbrsg.ac.ae

\section{REFERENCES}

[1] Darmstadt GL, Oot DA, Lawn JE. Newborn survival: changing the trajectory over the next decade. Health policy and planning. 2012 Jul 1; 27(suppl 3):iii1-5. doi:10.1093/heapol/czs054

[2] Lawn JE, Kinney MV, Black RE, Pitt C, Cousens S, Kerber K, Corbett E, Moran AC, Morrissey CS, Oestergaard MZ. Newborn survival: a multi-country analysis of a decade of change. Health policy and planning. 2012 Jul 1; 27(suppl 3):iii6-28. doi:10.1093/heapol/czs053

[3] Save The Children International. Surviving the First Day: State of the World's Mothers 2013. London, UK: Bill \& Melinda Gates Foundation. (2013). Retrieved from http://reliefweb.int/sites/reliefweb.in t/files/resources/State_of_World_M others_2013.pdf
[4] World Health Organization- Eastern Mediterranean Region. Saving the Lives of Mothers \& Children: Rising to the Challenge in the Eastern Mediterranean Region. http://www.emro.who.int/about who/mothers-and-children/backgrounddocuments.html (2013, accessed 1 January 2014).

[5] Chapman E, Reveiz L, Sangalang S, Manu C, Bonfill X, Muñoz S, Abalos E. A survey study identified global research priorities for decreasing maternal mortality. Journal of clinical epidemiology. 2014 Mar 31; 67(3): 314-24. doi:10.1016/j.jclinepi.2013.10.007

[6] Ronsmans C, Graham WJ, Lancet Maternal Survival Series steering group. Maternal mortality: who, when, where, and why. The Lancet. 2006 Oct 6; 368(9542): 1189-200. doi:10.1016/S0140-6736(06)69380$\mathrm{X}$

[7] Hutchins VL. Maternal and Child Health at the Millennium: Looking Back, Moving Forward. US Department of Health and Human Services, Health Resources and Services Administration, Maternal and Child Health Bureau; 2001.

[8] Council on Health Research for Development. Research Priorities. Retrieved from https: 
//www.healthresearchweb.org/en/na tional_priorities_for_health_researc h (2014, accessed 1 August 2015).

[9] UNICEF. The State of the World's Children 2012- Total live births in 2011: Healthy Newborn Network. (2012) Retrieved from www.healthynewbornnetwork.org

[10] Bhutta ZA. Child mortality in the Eastern Mediterranean Region: challenges and opportunities. EMHJ. 2013; 19(2). http://www.emro.who.int/emhjvolume-19-2013/volume-19-issue2/00editorial.html

[11] Bustreo F. Less than 1000 days to go for MDGs 4 and 5: where are we and what needs to be done? Eastern Mediterranean Health Journal. 2014 Jan 1; 20(1):3.

[12] Abou Zahr C. Safe motherhood: a brief history of the global movement 1947-2002. British Medical Bulletin. 2003 Dec 1; 67(1):13-25.

[13] Al Hussein, H. B. HRH. Saving the lives of mothers \& children: Rising to the challenges. Feature Address: WHO EMR 2013 Conference. (2013). Retrieved from http:/ /applications. emro. who.int/docs/IC_Meet_Rep_2013 _EN_14862.pdf
[14] Moonesar IA. The Role of UAE Health Professionals in Maternal and Child Health Policy. 2015 Scholarworks: Walden University.

[15] Eisenberger R, Huntington R, Hutchison S, Sowa, D. Perceived organizational support Journal of applied psychology. 1986; 71: 500-507.

[16] Allen DG, Shanock LR. Perceived organizational support and embeddedness as key mechanisms connecting socialization tactics to commitment and turnover among new employees. Journal of Organizational Behavior. 2013 Apr 1; 34(3): 350-69.

[17] Mitwalli HA, Al Ghamdi KM, Moussa NA. Perceptions, attitudes, and practices towards research among resident physicians in training in Saudi Arabia/Perceptions, attitudes et pratiques vis-à-vis de la recherche chez des médecins internes en formation en Arabiesaoudite. Eastern Mediterranean Health Journal. 2014 Feb 1; 20(2): 99.

[18] Shore LM, Wayne SJ. Commitment and employee behavior: comparison of affective commitment and continuance commitment with perceived organizational support. Journal of 
applied psychology. 1993 Oct; 78(5): 774.

[19] Andersen R. A behavioral model of families' use of health services. Research Ser.. 1968(25).

[20] Andersen RM. Revisiting the behavioral model and access to medical care: does it matter? Journal of health and social behavior. 1995 Mar 1: 1-0. doi:10.2307/2137284

[21] Andersen R, Newman JF. Societal and individual determinants of medical care utilization in the United States. Milbank Quarterly. 2005 Dec 1; 83(4): Onlineonly.doi:10.1177/1077558022378 08

[22] United Arab Emirates National Bureau of Statistics. Health 2011. Retrieved from http://www.uaestatistics.gov.ae/En glishHome/ReportDetailsEnglish/t abid/121/Default.aspx? ItemId=218 0\&PTID=104\&MenuId=1 (2013, accessed 1 July 2014).

[23] Krejcie RV, Morgan DW. Determining sample size for research activities. Educpsychol meas.

1970.

http://epm.sagepub.com/content/3

0/3/607.extract

[24] Wilson V. Research Methods: Sampling. Evidence Based Library and Information Practice. 2014 Jun $\quad 27 ; \quad 9(2): 45-7$. https://doaj.org/toc/1715-720X/9/2

[25] Chan W, Clark DJ, Ajani AE, Yap $\mathrm{CH}$, Andrianopoulos N, Brennan AL, Dinh DT, Shardey GC, Smith JA, Reid CM, Duffy SJ. Progress towards a national cardiac procedure database-development of the Australasian Society of Cardiac and Thoracic Surgeons (ASCTS) and Melbourne Interventional Group (MIG) registries. Heart, Lung and Circulation. 2011 Jan 31; 20(1):10-8.

doi:10.1016/j.hlc.2010.10.002

[26] Tabachnick BG, Fidell LS, Osterlind SJ. Using multivariate statistics. pp. 92.

[27] Arabi A, Rafii F, Cheraghi MA, Ghiyasvandian S. Nurses' policy influence: A concept analysis. Iranian journal of nursing and midwifery research. 2014 Jan 6; 19(3): 315-22.

[28] Weber D, Janson A, Nolan M, Wen LM, Rissel C. Female employees' perceptions of organisational support for breastfeeding at work: findings from an Australian health service workplace. International 
breastfeeding journal. 2011 Nov $30 ; 6(1): 1$.

[29] Johnston ML, Esposito N. Barriers and facilitators for breastfeeding among working women in the United States. Journal of Obstetric, Gynecologic, \& Neonatal Nursing. 2007 Jan 1; 36(1): 9-20.

[30] Rojjanasrirat W. Working women's breastfeeding experiences. MCN: The American Journal of Maternal/Child Nursing. 2004 Jul 1; 29(4): 222-7.

[31] Rosenberg D, Herman-Roloff A, Kennelly J, Handler A. Factors associated with improved $\mathrm{MCH}$ epidemiology functioning in state health agencies. Maternal and child health journal. 2011 Nov 1; 15(8): 1143-52.

[32] Klerman LV, Johnson KA, Chang $\mathrm{CH}$ Wright-Slaughter $\mathrm{P}$, Goodman DC. Accessibility of family planning services: impact of structural and organizational factors. Maternal and child health journal. 2007 Jan 1; 11(1): 19-26.

[33] Fraser MR. Bringing it all together: effective maternal and child health practice as a means to improve public health. Maternal and child health journal. $2013 \mathrm{Jul}$ 1; 17(5): 767-75.
[34] Creswell JW. Research design: Qualitative, quantitative, and mixed methods approaches. Sage publications; 2013 Mar 14. 